\title{
Prevalence of drug-drug interactions in geriatric patients at an ambulatory care pharmacy in a tertiary care teaching hospital
}

\author{
Rawabi Aljadani ${ }^{1^{*}}$ (D) and Mohammed Aseeri $^{2}$
}

\begin{abstract}
Objective: A cross-sectional study was performed from February to May 2015, to estimate the prevalence of drugdrug interactions in geriatric patients at the ambulatory care pharmacy at King Abdul-Aziz Medical City in Jeddah, Saudi Arabia.

Results: A total of 310 patients were included, with a mean age ( \pm SD) of $73.78 \pm 6.96$, and $48.70 \%$ were female. The overall prevalence of DDls of all categories was $90.64 \%$. Category B DDls was $55.80 \%$, category C DDls $87.74 \%$, category D DDls $51.93 \%$, and category X DDls $16.45 \%$. Atorvastatine plus omeprazole was identified as the most common interacting pair, with a prevalence of $25.26 \%$. Multivariate logistic regression analysis showed that category $\mathrm{D}$ or $X$ DDls are more likely to occur in the female patient $(\mathrm{OR}=1.79 ; 95 \% \mathrm{Cl} 1.07,2.97)$, the patient taking more than three medications $(\mathrm{OR}=22.62 ; 95 \% \mathrm{Cl} 2.93,174.83)$, and the patient with more than two conditions $(\mathrm{OR}=3.09 ; 95 \% \mathrm{Cl} 1.81$, 5.27).
\end{abstract}

Keywords: Prevalence, Drug-drug interactions, Geriatric, Ambulatory care, Pharmacy

\section{Introduction}

The issue of poly-pharmacy in geriatric patients has led to concern over an increase in drug-drug interactions (DDIs) prevalence. The precise minimum number of medications used to define "poly-pharmacy" varies but generally ranges from 5 to 10 [1]. Some combined medications may result in undesired pharmacodynamic or pharmacokinetic interactions, leading to under-treatment or harmful effects [2]. DDIs are an important cause of adverse drug reactions. Approximately $3-26 \%$ of all adverse drug reactions that require hospital admission are caused by drug-drug interactions [3]. Studies involving community-dwelling individuals report prevalence rates ranging from 4.6 to $17.6 \%[4,5]$. Studies conducted in hospital settings report prevalence rates ranging from 0.6 to $18.3 \%$, and a study carried out in a primary health care unit reports a prevalence rate of $6.8 \%$ [6-8].

\footnotetext{
*Correspondence: raar_66@hotmail.com; aljadanira@ngha.med.sa ${ }^{1}$ Pharmacy Department, King Saud bin AbdulAziz University for Health Sciences/King AbdulAziz Medical City, Riyadh, Saudi Arabia Full list of author information is available at the end of the article
}

Janchawee studied the pharmacoepidemiologic of potential drug-drug interactions in the outpatient pharmacy of a university hospital, where the overall rate of potential DDIs was $27.9 \%$, with a maximal value of $57.8 \%$ at the Department of Psychiatry. The rate of the most potentially significant interactions was $2.6 \%$, being the highest in the Department of Medicine (6\%), with isoniazid vs. rifampin as the most common interacting combination [9]. Another study of drug-drug interactions potential pattern in a tertiary care teaching hospital diabetic outpatient pharmacy, including a total of 182 patients, found a higher risk of DDIs among patients 51-60 years of age (43 patients, or $23.6 \%)$, It was found that $10(5.3 \%)$ of the potential drug-drug interactions were major, 5 (2.7\%) minor, and 174 (92.1\%) moderate, the most common potential drug-drug interaction observed was between metformin and enalapril $(n=64)$ [10]. Even though nature and prevalence of potential DDIs has been widely studied in different settings, DDIs nature in the ambulatory setting still a gray area with many contradictions, ambulatory care pharmacy serves a huge number of patients on a daily basis, should provide the highest 
possible level of quality, with the understanding that safety assurance is a cornerstone for the quality of any type of service. We realized the harmful effect of drugdrug interactions on patients' conditions and progress, as well as the effect on the pharmacoeconomics of the hospital itself. Based on that, this study was conducted to estimate the prevalence of drug-drug interactions in geriatric patients at the ambulatory care pharmacy at King Abdul-Aziz Medical City in Jeddah, Saudi Arabia.

\section{Main text \\ Methods \\ Study design}

This cross-sectional study was approved by King Abdullah International Medical Research Center (KAIMRC) and was conducted to estimate the prevalence of drugdrug interactions in geriatric patients at the ambulatory care pharmacy at King Abdul-Aziz Medical City in Jeddah, Saudi Arabia, from February to May 2015.

\section{Inclusion and exclusion criteria}

We included patients 65 years and older of both genders who visited the ambulatory care pharmacy at King Abdul-Aziz Medical City in Jeddah and who had a drug profile containing two or more medications, drug profile containing herbal products or topical products only including: creams, ointments, gels, patches, drops, sprays and inhalers were excluded.

\section{Data collection}

In this study, we did a retrospective review of 310 patients' medication profiles of ambulatory care pharmacy dispensed prescriptions. The assigned pharmacist retrieved the dispensed prescriptions randomly. Then the baseline characteristic and patient demographics data (including patient age, gender, number of drugs, and chronic illness at the time of dispensing) and the patient drug profile data (including drug, dose, and route) were collected. The drug profile for each patient was analyzed by Lexi-Interact (a comprehensive drug-to-drug, drug-to-herb, and herb-to-herb interaction analysis program); Lexi-Interact categorized DDIs into five categories according to its risk rating, category A: data have not demonstrated either pharmacodynamic or pharmacokinetic interactions between the specified medications, B: the specified medications may interact with each other, but there is little to no evidence of clinical concern resulting from their concomitant use, $\mathrm{C}$ : the medications agents may interact with each other in a clinically significant manner, but the benefits of concomitant use of these two medications usually outweigh the risks, D: the two medications may interact with each other in a clinically significant manner, a patient-specific assessment must be conducted to determine whether the benefits of concomitant therapy outweigh the risks, and X: the specified medications may interact with each other in a clinically significant manner, but the risks associated with concomitant use of these medications usually outweigh the benefits [11].

\section{Statistical analysis}

Descriptive statistics were used to describe continuous (Mean $\pm \mathrm{SD}$ ) and categorical variables (frequency and percent). We used Chi square test to assess the association between D or X DDIs and categorical variables, while Independent- $t$ test was used to assess the association between $\mathrm{D}$ or X DDIs and continuous variables. Prevalence was used to determine the proportion of geriatric patients visiting the ambulatory care pharmacy who have a medication profile containing at least one interacting pair with no regard for DDI risk rating. Prevalence was also used to determine the proportion of geriatric patients with at least one interacting pair for each drug-drug interaction risk rating $(\mathrm{B}, \mathrm{C}, \mathrm{D}$, and $\mathrm{X})$ alone. It was also used to estimate the proportion of patients for each one of the most common interacting pairs. Multivariate logistic regression analysis was used to determine if gender, age, number of drugs, and chronic conditions can predict $\mathrm{D}$ and $\mathrm{X}$ DDIs risk rating prevalence. The odds ratio (OR) and respective confidence interval (CI) was calculated in this analysis for each variable. Wald Chi square test $\mathrm{P}$ values $<0.05$ were considered statistically significant. Using IBM SPSS Statistics for Microsoft, Version 22.0, we preformed all the statistical analysis [12].

\section{Results}

A total of 310 patients were included in this study, with a mean age of $73.8( \pm S D 7)$ years. Approximately half of them $(48.70 \%)$ were female. The majority $(91.3 \%)$ had a prescription with more than three medications, and 62.3\% had more than two chronic conditions. Baseline characteristics and patient demographics are listed in Table 1.

\section{Drug-drug interactions prevalence}

The overall prevalence of DDIs of all categories was 90.64\% (95\% CI 86.8\%, 93.6\%). Category B DDIs prevalence was $55.80 \%$ (95\% CI 50.1\%, 61.4\%), category C DDIs 87.74\% (95\% CI 83.6\%, 91.2\%), category D DDIs 51.93\% (95\% CI 46.2\%, 57.6\%), and category X interacting pairs $16.45 \%$ (95\% CI 12.5\%, 21.1\%).

\section{Most common interacting pairs}

Atorvastatin + omeprazole was identified as the most common interacting pair, with a prevalence of $25.26 \%$. Next was atorvastatin + calcium, with a prevalence of 
Table 1 Baseline characteristics and patient demographics

\begin{tabular}{|c|c|c|c|c|c|c|c|c|}
\hline \multirow[t]{3}{*}{ Factor } & \multirow[t]{3}{*}{ Reference } & \multirow[t]{3}{*}{ Mean } & \multirow[t]{3}{*}{ $\pm S D$} & \multicolumn{4}{|c|}{ Interactions D or X DDIs } & \multirow[t]{3}{*}{$P$} \\
\hline & & & & \multicolumn{2}{|l|}{ No } & \multicolumn{2}{|l|}{ Yes } & \\
\hline & & & & Mean & $\pm S D$ & Mean & $\pm S D$ & \\
\hline \multirow[t]{2}{*}{ Age } & & 73.8 & 7.0 & 74.2 & 7.1 & 73.5 & 6.8 & 0.412 \\
\hline & & $\mathrm{N}$ & $\%$ & $N$ & $\%$ & $\mathbf{N}$ & $\%$ & \\
\hline \multirow[t]{2}{*}{ Gender } & Female & 151 & 48.7 & 56 & 37.1 & 95 & 62.9 & 0.092 \\
\hline & Male & 159 & 51.3 & 74 & 46.5 & 85 & 53.5 & \\
\hline \multirow{2}{*}{$\begin{array}{l}\text { Number of pre- } \\
\text { scribed medica- } \\
\text { tions }\end{array}$} & 3 or fewer medications & 27 & 8.7 & 26 & 96.3 & 1 & 3.7 & $0.001^{*}$ \\
\hline & More than 3 medications & 283 & 91.3 & 104 & 36.7 & 179 & 63.3 & \\
\hline \multirow{2}{*}{$\begin{array}{l}\text { Number of chronic } \\
\text { conditions }\end{array}$} & 2 or fewer conditions & 117 & 37.7 & 74 & 63.2 & 43 & 36.8 & $0.001^{*}$ \\
\hline & More than 2 conditions & 193 & 62.3 & 56 & 29 & 137 & 71 & \\
\hline
\end{tabular}

* Chi square test is significant $a=0.05$

$22.90 \%$. The prevalence of all the identified most common interacting pairs, their risk rating, severity, reliability rating, predicted impact on the clinical outcome, and suggested patient management plan are all mentioned in Table 2 .

\section{Drug-drug interactions predictors}

Univariate logistic regression analysis including all 310 patients showed that the odds of D or X DDIs were 44 times higher when more than three medications were prescribed $(\mathrm{OR}=44.75$, 95\% CI 5.99, 334.61). The percentage of $\mathrm{D}$ or X DDIs was higher in patients taking more than three medications $(3.7 \%$ were using $\leq 3$ medications vs. $63.3 \%$ using $>3$ medications, $\mathrm{P}=0.001$ ). Also, univariate analysis revealed that the odds of D or X DDIs were four times higher when the patient had more than two chronic conditions ( $\mathrm{OR}=4.21,95 \%$ CI 2.59, 6.86). When we compare the number of chronic conditions among patients with D or X DDIs, we can see that the percentage of patients with more than two conditions who have $\mathrm{D}$ or $\mathrm{X}$ DDIs almost doubles the percentage of patients with two or fewer conditions (36.8\% with $\leq 2$ conditions vs. $71.0 \%>2$ conditions, $\mathrm{P}=0.001)$. The combined effects of all the factors were further investigated by conducting a multivariate logistic regression analysis, which indicated that D or X DDIs were more likely to occur in the female patient $(\mathrm{OR}=1.79 ; 95 \% \mathrm{CI} 1.07$, $2.97)$, the patient taking more than three medications $(\mathrm{OR}=22.62 ; 95 \% \mathrm{CI} 2.93,174.83)$, and the patient with more than two conditions (OR $=3.09 ; 95 \%$ CI 1.81, 5.27). Regression analysis results are stated in Table 3.

\section{Discussion}

The overall DDIs prevalence estimate (90.64\%) could be misleading if not linked to the expected clinical impact of each category, to correctly judge these results, we must consider that category $\mathrm{C}$, which has the highest influence on this estimate, has less of a clinical impact compared to category D and X DDIs. D and X DDIs' estimated prevalence of 51.93 and $16.45 \%$ respectively reflects the need for in-depth investigations. Björkman et al. studied drugdrug interactions in elderly outpatients in six European countries. They found that $46 \%$ of patients had at least one potential clinically significant DDI, and $10 \%$ of these DDIs were classified as (to be avoided) according to the Swedish interaction classification system [13]. Venturini et al. reported a moderate DDIs prevalence of $69.9 \%$, and a $21.2 \%$ prevalence of major DDIs. The difference in the results may be attributed to the use of different DDIs analysis database; DDIs categories differ according to the database used, the difference in the population characteristics, and the sample size of these studies [14]. A direct comparison can't be done without a further adjustment for these factors. Other studies reported the prevalence of DDIs either in different settings, such as the hospital, or in a specific population, such as cancer patients, so also can't be directly compared with the results of this study.

Several studies investigated the most common interacting pairs, and different results were reported. This is to be expected due to the variations in the medication availability and medical practice of each institute. Of the top 20 identified most common interacting pairs we identified, atorvastatine was responsible for four, as was aspirin. Hypoglycemic agents, PPIs, and calcium were each responsible for three interacting pairs. Dinesh reported aspirin as the fourth-ranked of the top 10 medications with a high risk for DDIs [10].

Our multivariate logistic regression analysis results agree with the results of many previous studies. Neto et al. studied the prevalence and predictors of potential drug-drug interactions in the elderly in the Brazilian 


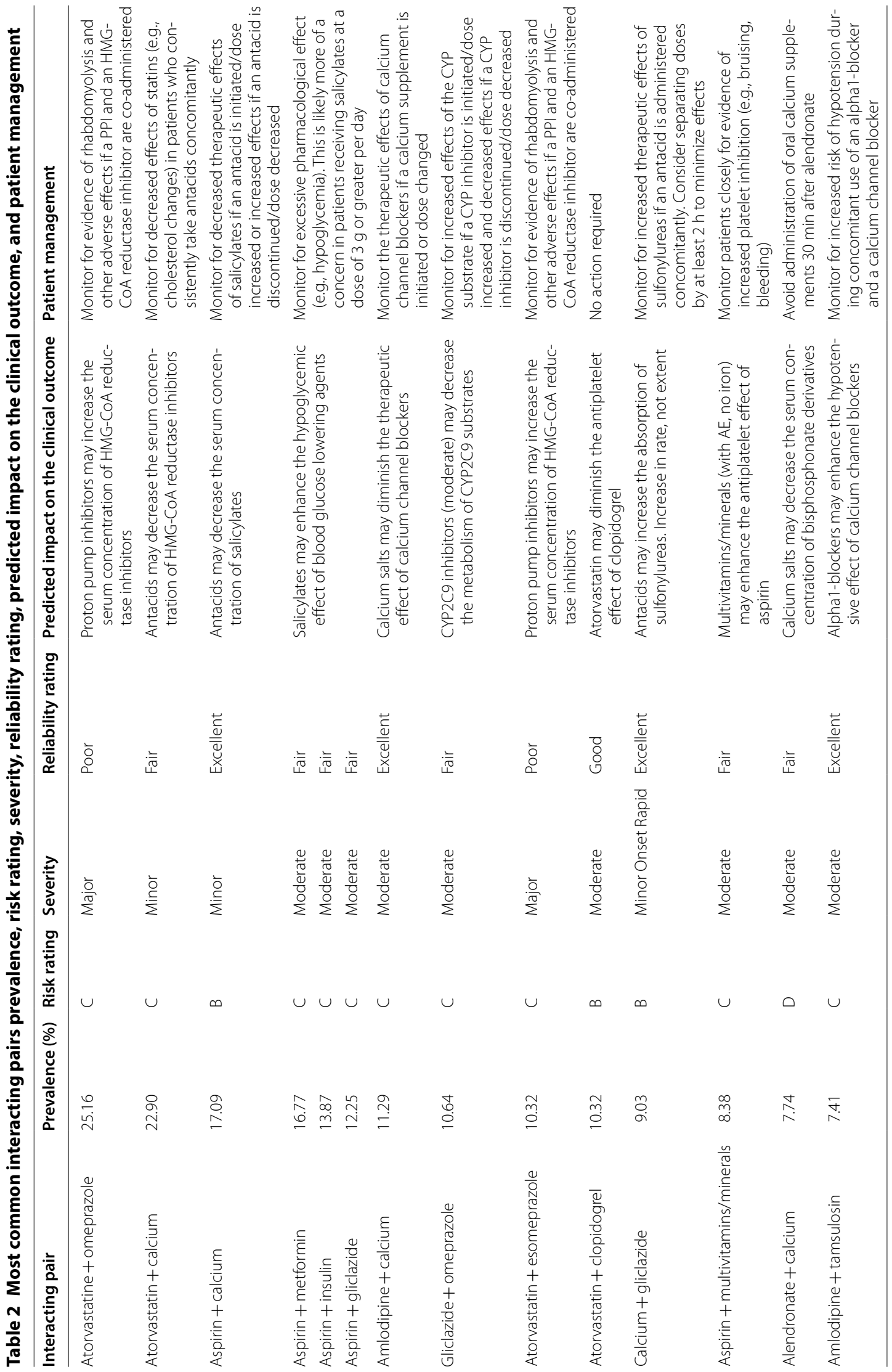




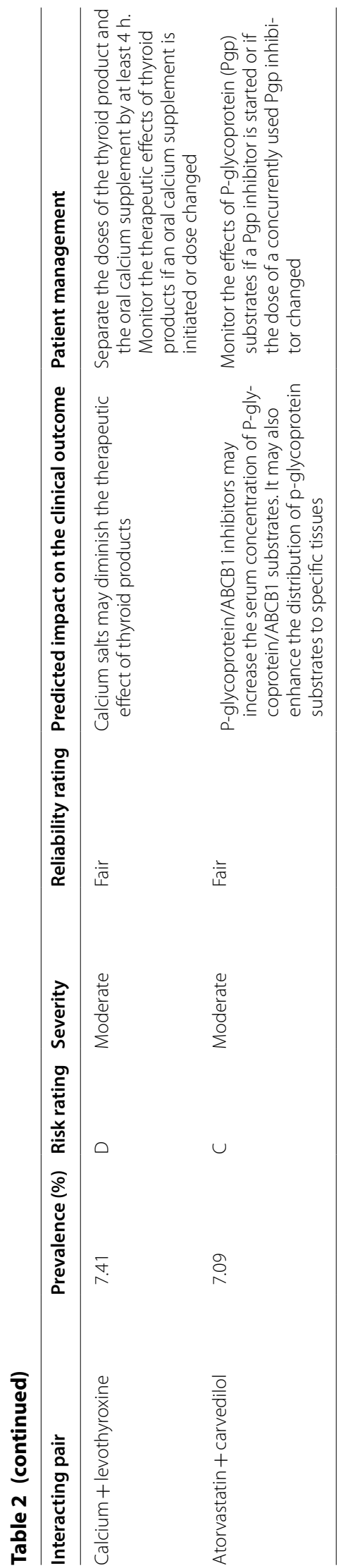


Table 3 Logistic regression analysis results for category D or X DDls potential predictors

\begin{tabular}{|c|c|c|c|c|c|c|c|c|c|}
\hline \multirow[t]{3}{*}{ Factor } & \multirow[t]{3}{*}{ Reference } & \multicolumn{4}{|c|}{ Univariate analysis } & \multicolumn{4}{|c|}{ Multivariate analysis } \\
\hline & & \multirow[t]{2}{*}{ OR } & \multicolumn{2}{|c|}{$95 \% \mathrm{Cl}$ for OR } & \multirow[t]{2}{*}{$\mathbf{P}$} & \multirow[t]{2}{*}{ OR } & \multicolumn{2}{|c|}{$95 \% \mathrm{Cl}$ for $\mathrm{OR}$} & \multirow[t]{2}{*}{$\mathbf{P}$} \\
\hline & & & Lower & Upper & & & Lower & Upper & \\
\hline Age & & 0.99 & 0.96 & 1.02 & 0.411 & 0.983 & 0.95 & 1.02 & 0.348 \\
\hline Female & Male & 1.48 & 0.94 & 2.33 & 0.092 & 1.79 & 1.07 & 2.97 & $0.026^{*}$ \\
\hline More than 3 medications & 3 or fewer medications & 44.75 & 5.99 & 334.61 & $0.001^{*}$ & 22.62 & 2.93 & 174.83 & $0.003^{*}$ \\
\hline More than 2 conditions & 2 of fewer conditions & 4.21 & 2.59 & 6.86 & $0.001^{*}$ & 3.09 & 1.81 & 5.27 & $0.001^{*}$ \\
\hline
\end{tabular}

*Wald Chi square test is significant $a=0$

primary public health system. Their multivariate regression analysis results showed that being female and having three or more diagnosed diseases were positively associated with exposure to DDIs $(\mathrm{OR}=2.49 ; 95 \% \mathrm{CI} 2.29,2.75$ and $\mathrm{OR}=6.43 ; 95 \%$ CI $3.25,12.44$, respectively) [15]. Teixeira et al. performed a multivariate regression that showed that patients with three to five medications have high odds of DDIs (OR $=4.84 ; 95 \%$ CI 2.85, 7.91), while patients with six or more medications have higher odds of DDIs (OR $=25.11 ; 95 \%$ CI 9.98, 48.63) [16].

\section{Conclusion}

The prevalence of DDIs among geriatric patients attending the ambulatory care pharmacy was high. This indicates the need for special care while handling their prescriptions. Even though the majority of the most common interacting pairs (top 20) were category $C$, we still need to look for $\mathrm{D}$ and $\mathrm{X}$ interacting pairs carefully. Finally, the identified DDIs' main predictors of number of prescribed medications (more than four) and number of chronic conditions (more than three) could guide us to provide better care and to develop a safer practice.

\section{Limitations}

DDIs analysis was based only on one database (LexiInteract). Our study was conducted in a specific type of setting and population, which is why our findings are not generalizable to other settings or different populations, especially populations such as cancer or transplant patients. The study may underestimate the prevalence of DDIs in these populations. Additionally, non-prescribed medications such as over-the-counter and herbal products were excluded, which may lead to an underestimate of the prevalence of DDIs in our sample. Despite these limitations, the results of this study represent a step forward in exploring the occurrence and nature of DDIs in geriatric patients attending the ambulatory care pharmacy.
Abbreviations

DDIs: drug-drug interactions; KAIMRC: King Abdullah International Medical Research Center

\section{Authors' contributions}

RA designed the study, collected the data, performed the statistical analysis, interprets the results, and drafted the manuscript. MA participated in the study design, and helped to draft the manuscript. Both authors read and approved the final manuscript.

\section{Author details}

${ }^{1}$ Pharmacy Department, King Saud bin AbdulAziz University for Health Sciences/King AbdulAziz Medical City, Riyadh, Saudi Arabia. ${ }^{2}$ Clinical Pharmacy Services, Pharmacy Department, King Saud bin AbdulAziz University for Health Sciences/King AbdulAziz Medical City, PO Box 9515, Jeddah 21423, Saudi Arabia.

\section{Acknowledgements}

We thank Dr. Anwar Ahmed and Dr. Fayssal Farahat for their useful criticism and their constructive recommendations.

\section{Competing interests}

The authors declare that they have no competing interests.

\section{Availability of data and materials}

The datasets generated and analyzed during the current study are not publicly available to protect participant information confidentiality but are available from the corresponding author on reasonable request.

\section{Consent to publish \\ Not applicable.}

\section{Ethical approval and consent to participate}

This study was conducted with ethical approval from the Ethical Committee of King Abdullah International Medical Research Center (KAIMRC). The need for consent was waived by the IRB, the decision number is (RJ15/003/J), the research didn't involve any procedure or represents any harm to participants, and to avoid any potential breach of confidentiality necessary participant identifiers were removed from data files, Identifiers were stored in a physically separated and secured location of the data files.

\section{Funding}

The authors have no funding to report.

\section{Publisher's Note}

Springer Nature remains neutral with regard to jurisdictional claims in published maps and institutional affiliations.

Received: 22 August 2017 Accepted: 30 March 2018

Published online: 05 April 2018 


\section{References}

1. Astrand B, Astrand E, Antonov K, Petersson G. Detection of potential drug interactions - a model for a national pharmacy register. Eur J Clin Pharmacol. 2006;62:749-56.

2. Peyriere H, Cassan S, Floutard E, et al. Adverse drug events associated with hospital admission. Ann Pharmocother. 2003;37:5-11.

3. Ferner RE, Aronson JK. Communicating information about drug safety. BMJ. 2006;333:143.

4. Secoli SR, Figueras A, Lebrao ML, de Lima FD, Santos JL. Risk of potential drug-drug interactions among Brazilian elderly: a population-based, cross-sectional study. Drugs Aging. 2010;27:759-70.

5. Bleich GW, Bleich A, Chiamulera P, et al. Frequency of potential interactions between drugs in medical prescriptions in a city in southern Brazil. Sao Paulo Med J. 2009;127:206-10.

6. Cruciol-Souza JM, Thomson JC. A pharmacoepidemiologic study of drug interactions in a Brazilian teaching hospital. Clinics (Sao Paulo). 2006;61:515-20.

7. Silva NMO, Carvalho RP, Bernardes ACA et al. Potential drug interaction evaluation in medical prescriptions in a public hospital specialized in women care, in Campinas, SP. Rev Ciênc Farm Básica Apl. 2010:31:171-6.

8. Codagnone Neto V, Garcia VP, Santa Helena ET. Possible pharmacological interactions in hypertensive and/or diabetic elderly in family health units at Blumenau (SC). Braz J Pharm Sci. 2010;46:795-804
9. Janchawee B, Wongpoowarak W, Owatranporn T, et al. Pharmacoepidemiologic study of potential drug interactions in outpatients of a university hospital in Thailand. J Clin Pharm Ther. 2005;30:13-20.

10. Dinesh KU, Subish P, Pranaya M, et al. Pattern of potential drug-drug interactions in diabetic out-patients in a tertiary care teaching hospital in Nepal. Med J Malaysia. 2007;62:294-8.

11. Lexicomp Online, Lexi-Interact ${ }^{\mathrm{TM}}$ Online, Hudson, Ohio: Lexi-Comp, Inc 2015. http://www.uptodate.com/crlsql/interact/frameset.jsp. Accessed Feb 2018

12. IBM Corp. Released 2013. IBM SPSS Statistics for Macintosh, Version 22.0. Armonk: IBM Corp.

13. Bjorkman IK, Fastbom J, Schmidt IK, Bernsten CB, The Pharmaceutical Care Of The Elderly In Europe Research (PEER) Group. Drug-drug interactions in the elderly. Ann Pharmacother. 2002;36:1675-81.

14. Venturini C, Engroff P, Ely L, et al. Gender differences, polypharmacy, and potential pharmacological interactions in the elderly. Clinics. 2011;66(11):1867-72

15. Neto P, Nobili A, Marusic S, et al. Prevalence and predictors of potential drug-drug interactions in the elderly: a cross-sectional study in the Brazilian primary public health system. J Pharm Pharm Sci. 2012;15(2):344-54.

16. Teixeira JJV, Crozatti MTL, dos Santos CA, Romano-Lieber NS. Potential drug-drug interactions in prescriptions to patients over 45 years of age in primary care, Southern Brazil. PLoS ONE. 2012;7(10):47062.
Ready to submit your research? Choose BMC and benefit from:

- fast, convenient online submission

- thorough peer review by experienced researchers in your field

- rapid publication on acceptance

- support for research data, including large and complex data types

- gold Open Access which fosters wider collaboration and increased citations

- maximum visibility for your research: over 100M website views per year

At BMC, research is always in progress.

Learn more biomedcentral.com/submissions 